\title{
Automatic Condition Monitoring of Industrial Rolling-Element Bearings Using Motor's Vibration and Current Analysis
}

\author{
Zhenyu Yang \\ Department of Energy Technology, Aalborg University, Esbjerg Campus, Niels Bohrs Vej 8, 6700 Esbjerg, Denmark \\ Correspondence should be addressed to Zhenyu Yang; yang@et.aau.dk
}

Received 26 January 2015; Accepted 8 March 2015

Academic Editor: Jiawei Xiang

Copyright (C) 2015 Zhenyu Yang. This is an open access article distributed under the Creative Commons Attribution License, which permits unrestricted use, distribution, and reproduction in any medium, provided the original work is properly cited.

\begin{abstract}
An automatic condition monitoring for a class of industrial rolling-element bearings is developed based on the vibration as well as stator current analysis. The considered fault scenarios include a single-point defect, multiple-point defects, and a type of distributed defect. Motivated by the potential commercialization, the developed system is promoted mainly using off-the-shelf techniques, that is, the high-frequency resonance technique with envelope detection and the average of short-time Fourier transform. In order to test the flexibility and robustness, the monitoring performance is extensively studied under diverse operating conditions: different sensor locations, motor speeds, loading conditions, and data samples from different time segments. The experimental results showed the powerful capability of vibration analysis in the bearing point defect fault diagnosis. The current analysis also showed a moderate capability in diagnosis of point defect faults depending on the type of fault, severity of the fault, and the operational condition. The temporal feature indicated a feasibility to detect generalized roughness fault. The practical issues, such as deviations of predicted characteristic frequencies, sideband effects, time-average of spectra, and selection of fault index and thresholds, are also discussed. The experimental work shows a huge potential to use some simple methods for successful diagnosis of industrial bearing systems.
\end{abstract}

\section{Introduction}

The bearing component plays a critical role in rotational machines; its functionality is directly relevant to the operational performance and consequently the reliability and safety of these machines and relevant systems [1]. It has been discovered that bearing defects can account for up to $51 \%$ of different AC motor faults [2]. Some cost-effective early fault detection and diagnosis (FDD) of potential bearing faults is very important and necessary with respect to the reliable operation and reduction of system breakdown time [3-7].

As shown in Figure 1, a standard rolling-element bearing consists of an inner and outer raceway with a set of balls or rolling elements placed between these two raceways and held by a cage. Bearing faults could happen with the raceways and ball or rolling element as well as the cage, such as a scratch on the surface of the raceway(s). The bearing faults can be caused due to improper installation of the bearing onto the shaft or into the housing, misalignment of the bearing, contamination, corrosion, improper lubrication, or simply wear $[3,6,8]$. According to different geometric characteristics, the bearing faults can be classified into two categories, that is, point defects and distributed defects [8]. A point defect is often referred to as a localized defect on a bearing component surface, such as a pit, spall, or short scratch on the raceway surface or ball surface $[9,10]$. A point defect can be single or multiple [11]. A distributed defect is often referred to as some defect relevant to a large area of irregular or deformed surface(s), such as generalized roughness [10], waviness, or off-size rolling elements [8].

There is a huge amount of research work and literature dedicated to bearing condition monitoring and the bearing FDD in recent decades [12]. Some relevant review papers can be found in $[2,4,6,8,13-15]$ and references therein. FDD can be carried out based on the measurement data from the machine vibration response $[14,16,17]$, the acoustic emission response [8], or the stator current(s) $[18,19]$. The analysis can be signal-based (model-free) methods $[18,20]$ or modelbased methods $[14,21-23]$. The techniques can be timedomain oriented, such as RMS, crest factor, and kurtosis [3], 


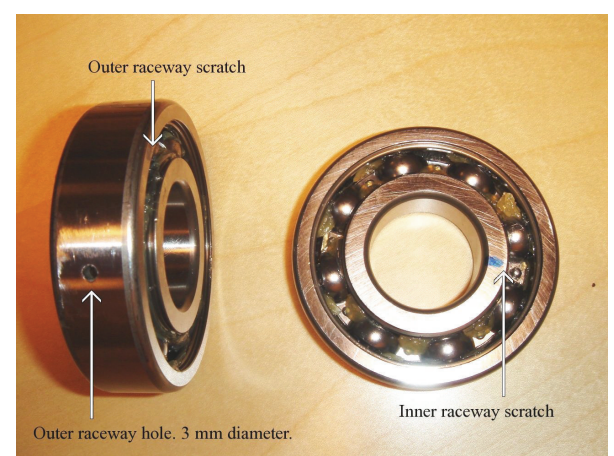

FIGURE 1: Considered NSK 6305 ball bearings with some artificial inner raceway/outer raceway point defects [27].

frequency-domain oriented, such as the envelope method and high-frequency resonance method [9], or the combination of time and frequency domains, such as the wavelet method and short-time Fourier transform (STFT) method [24-27]. The FDD focus can be on a single-point defect [9], multiple-point defects [11], or generalized roughness [10].

The vibration based methods have been most popularly and extensively studied. Even some international standard has been published [28]. The motivation for using vibration analysis is due to the fact that the mechanical vibration consists of the direct reflection of the possible bearing defect and furthermore any point defect will excite vibration at some specific frequency and its harmonies, depending on which bearing component contains the defect. These specific frequencies are referred to as (specific fault's) characteristic frequencies (CFs) $[3,8,14]$. These $\mathrm{CFs}$ can be predicted based on the shaft speed and the bearing geometry. However, practically these CF signals are modulated in the vibration measurement; some demodulation techniques, such as envelope detection or high-frequency resonance techniques, are often required to extract these frequencies. By comparing the generated spectra based on a nominal operation and a fault-suspected operation around these CFs, the FDD can be carried out. If some quantitative information and indices are defined, an automatic diagnostic system can be developed based on, for example, a pattern recognition technique [8] or an amplitude modulation detector [29].

The effects of machine speeds on the bearing fault detection is investigated in [30], and it was observed that speed variations can retard or temporarily mask the bearing fault effect in the measured machine vibration. The influence of different loading conditions on inner raceway fault detection is investigated in [7]. These issues had previously not received much attention. In order to cope with potential nonstationary situations, a method using the wavelet to analyze the vibration signal so as to trade off the timefrequency resolution is proposed in [25]. Reference [21] proposed a neural network-based diagnosis method so as to cope with potential uncertainties and nonlinearities ignored by theoretical analysis. A two-step data mining approach is employed in [17] for a plastic bearing fault diagnosis. There is no doubt that these artificial intelligence methods can provide an enhanced and more powerful capability for bearing fault diagnosis compared to conventional spectrum methods; however, the parameter selection and the computation load of these methods can be very challenging when they are going to be employed in a real-world application. Nevertheless, compared with extensive studies on point defects, there are few studies on distributed defects, even though this kind of fault is common in industrial applications $[8,10]$. The reason mainly lies in the fact that there are not any characteristic frequencies, reflected by vibration signals, associated with this type of fault.

The vibration based FDD requires the installation of vibration transducers on machines; this often leads to extra expenses compared with standard machines. An alternative method is to use the stator current measurement for bearing FDD $[13,18,19,22,24,26,31,32]$. The benefit of this idea is quite obvious with respect to the fact that, in many motordriven rotational applications, the state current is already measured for some specific purpose(s), for example, for motor speed control. Reference [31] considered the generation of eccentricities due to some bearing fault, which causes some periodical changes of the machine inductances. The bearing defect exhibited peaks in current spectra at some modulated CFs depending on the type of fault. This model is extended in [22] by taking torque variations into consideration. In general, compared with extensive work and results focusing on vibration based analysis, the current based bearing fault FDD approach is far more mature $[4,13,18,32]$. Nevertheless, to the best of our knowledge, there is not much extensive work being done about how much difference the vibration analysis and the current analysis could lead to [23, 33].

Another motivation of this work is to check the possibility of industrialization of some existing bearing FDD methods. In particular, the feasibility of using the current signature analysis for bearing FDD can be quite interesting to many industrial pump producers. For instance, many commercial pump systems already have the motor current measured inside the integrated control module, which is apparently used by the pump speed controller. If possible, it would be quite cost-effective to use the already available motor current measurement instead of installing extra vibration sensors for bearing health monitoring. In addition, the integration of the developed FDD algorithm into the existing control module is also quite straightforward.

The contribution of this work lies in the following aspects: (1) there is a bearing FDD study by implementing both vibration based methods and current based methods on the same machine system; (2) the considered bearing fault scenarios include a single-point defect, multiple-point defects, and a type of generalized roughness; (3) the FDD performance is evaluated under extensively diverse conditions, such as different sensor locations, different motor speeds, different loading conditions, and data samples from different time segments; (4) many practical issues relevant to automatic monitoring implementation are explored and discussed, such as practical deviations of predicted CFs, sideband effects, 
time-average of spectra, and selection of fault index and thresholds for FDD.

In the following, the high-frequency resonance technique with envelope detection is employed for vibration analysis. The amplitude average of a set of STFTs is used for the current spectra analysis. By the end, a simple automatic FDD scheme is proposed by checking the relative deviations of the spectra around specific modulated CFs. The rest of this paper is organized as follows: Section 2 introduces fault characteristic frequencies and feature extraction methods employed here; Section 3 gives a brief description of the considered testing setup and apparatus; Section 4 presents experimental results from vibration and current signature analysis; Section 5 proposes an automatic bearing FDD system. Finally we discuss and conclude the paper in Section 6.

\section{Characteristic Frequencies and Feature Extraction Methods}

2.1. Fault Scenarios. Along with a set of healthy bearings, one defective bearing is designed to have a scratch on the inner raceway, which serves as (single-point) inner raceway defect scenario. The second defective bearing has a hole with a diameter of $3 \mathrm{~mm}$ through the outer raceway and a scratch on the outer raceway as well. The second bearing services as (multipoint) outer raceway defect scenario. This type of fault is used to emulate an extremely serious (multiple-) point defect situation. Both bearings can be seen in Figure 1. The third defective bearing is designed without lubricant, so that it services as a generalized roughness condition. The FDD algorithms are tested for different scenarios under different operating conditions, that is,

(i) three different loading configurations,

(ii) different motor speeds,

(iii) different vibration measurement positions,

(iv) data samples from different time intervals.

Both the vibration and state current analyses are carried out and compared in the following section.

2.2. Fault Characteristic Frequencies. For each type of bearing point fault, a specific frequency, named characteristic frequency $(\mathrm{CF})$, is associated. This frequency corresponds to a periodicity by which an anomaly appears due to the existence of a specific fault. These CFs can be predicted based on the bearing's geometry and the rotating speed $[14,20,22]$ under the ideal situation, such as

$$
\begin{gathered}
F_{c}=\frac{1}{2} F_{s}\left(1-\frac{D_{b} \cos \alpha}{D_{c}}\right), \\
F_{\text {ri }}=\frac{N_{b}}{2} F_{s}\left(1+\frac{D_{b} \cos \alpha}{D_{c}}\right), \\
F_{\text {ro }}=\frac{N_{b}}{2} F_{s}\left(1-\frac{D_{b} \cos \alpha}{D_{c}}\right), \\
F_{b}=\frac{D_{c}}{2 D_{b}} F_{s}\left(1-\frac{D_{b}^{2} \cos ^{2} \alpha}{D_{c}^{2}}\right),
\end{gathered}
$$

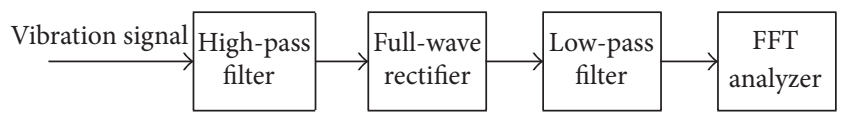

FIGURE 2: Sketch of envelope detection method [27].

where the fundamental cage fault frequency, denoted as $F_{c}$, is the frequency by which the balls pass a defective cage point; the inner/outer raceway fault frequency, denoted as $F_{\mathrm{ri}} / F_{\mathrm{ro}}$, is the frequency by which the balls pass a defective inner/outer raceway point. $F_{b} / F_{s}$ is the ball/motor shaft rotational frequency, $N_{b}$ is the number of balls, $D_{b} / D_{c}$ is the diameter of the ball/cage, and $\alpha$ is the contact angle between the raceway and balls. For our considered bearing elements, these parameters are $D_{c}=43 \mathrm{~mm}, D_{b}=10 \mathrm{~mm}, N_{b}=8$, and $\alpha=0$. It should be noticed that this prediction is based on the assumption of pure rolling races; however, in reality, some sliding motion may occur which can cause deviations of characteristic frequencies $[8,25,30]$.

2.3. Envelope Detection. The potentially distinguishable vibration due to a bearing point defect is often modulated in the amplitudes of high-frequency vibration measurement [14]. Thereby a demodulation of the measured data is required before any specific characteristic feature can be extracted. The envelope detection technique can be used for this demodulation purpose. The envelope detection method we used here is shown in Figure 2. For our considered case, the cut-off frequency of the high-pass filter is selected as $2500 \mathrm{~Hz}$, since the machine's mechanical structure has a number of resonances before that frequency and one distinguished resonance afterwards. This resonance analysis was carried out by properly hitting the motor with a hammer and then analyzing the measured vibration [34]. The highpass filtered signal then passes through a full-wave rectifier, and finally a low-pass filter is used to filter out the higher harmonics of the rectified signal, where the low-pass filter is used with a cut-off frequency of $500 \mathrm{~Hz}$. The low-pass cut-off frequency is selected at least double of the highest CF, which is $F_{\mathrm{ri}}=246.35 \mathrm{~Hz}$ at full speed in our case. This is also consistent with the notation given in [8] that for most standard bearings the defect CFs are usually less than $500 \mathrm{~Hz}$.

2.4. Short-Time Fourier Transform. As one of the simplest time-frequency techniques, the short-time Fourier transform (STFT) is employed for current signal analysis. The STFT of a time signal $x(t)$ over a time window $w(t)$ with a length of $T$ is defined as

$$
\operatorname{STFT}(t, f)=\int_{t-T / 2}^{t+T / 2} x(\tau) w(\tau-t) e^{-j 2 \pi f \tau} d \tau .
$$

Initially, the STFT is used to handle nonstationary signals. Here we use the (magnitude) average in frequency of a set of STFTs generated at different time segments (could be partially overlapped) for a stationary signal in order to "filter" out the frequency noise in the spectra. We call this averaged 
STFT magnitude mean of STFTs of the considered signal in the following; that is,

$$
\text { Mean_STFT }(f)=\frac{1}{K} \sum_{k=0}^{K}\left|\operatorname{STFT}\left(t_{k}, f\right)\right|,
$$

where $K$ is the number of STFTs. Usage of the mean STFT can help get rid of some rare situations and achieve a smoother spectrum than the standard STFT.

2.5. Current Characteristic Frequencies. The characteristic frequency of a bearing fault may also be reflected in the stator current measurement besides vibration measurement [18]. Intuitively, a bearing point defect can possibly cause a radial motion between the rotor and stator. This mechanical displacement then causes variations of the air gap flux density inside the motor. Correspondingly, this changed air gap flux produces the variation of stator currents at some specific frequencies, which we referred to as current characteristic frequencies (CCFs). These CCFs can be predicted according to $[13,22,24,26,31]$. Consider

$$
F_{\text {ccf }}=\left|F_{e} \pm m F_{i, o}\right| \text {, }
$$

where integer $m=1,2,3, \ldots, F_{e}$ is the stator power supply frequency, and $F_{i, o}$ is one of the CFs specified in (1).

\section{Testing Setup and Apparatus}

A type of $3 \mathrm{~kW}$ three-phase induction motor (MG100LC228FT130-D1) is used for testing purpose. This type of motor has two bearings with different sizes: the big one is mounted at the load end of the shaft and the small one is at the back end of the motor. The load side bearing is considered for health monitoring. A set of accelerometers (W352B10) produced by Piezotronics is used to measure the vibrations of the motor. This type of sensor has a frequency range of $1-10000 \mathrm{~Hz}$ and can measure a peak acceleration up to $4900 \mathrm{~m} / \mathrm{s}^{2}$, while the sensor itself only weighs $0.7 \mathrm{gram}$. The selected accelerometer is quite sensitive, and the 4294 Brüel \& Kjær calibrator is therefore used to calibrate all sensors before they are deployed on the motor setup. The measurements of the phase current are carried out by standard electrical equipment. In order to determine the motor shaft speed, an optical tachometer is used. The data acquisition is handled by the Brüel \& Kjær Dyn-X 3560B 5 channel data recorder. For the vibration measurements, the data recorder sets up a highpass filter with a cut-off frequency of $7 \mathrm{~Hz}$ in order to remove all possible DC offsets.

The sampling rate is selected as $16384 \mathrm{~Hz}$, which is the highest sample rate the instrument can handle. The ISO 10816 standard is followed for selection of accelerometer positions [28]. As shown in Figure 3, all six positions are examined and analyzed. In the following we only distinguish vibration measurements as radial position measurement or axial position measurement. The bearings used in this study are NSK 6305. A set of defective bearings are artificially designed so as to study different fault scenarios.

The motor setup is arranged into three configurations in order to study different load influences.

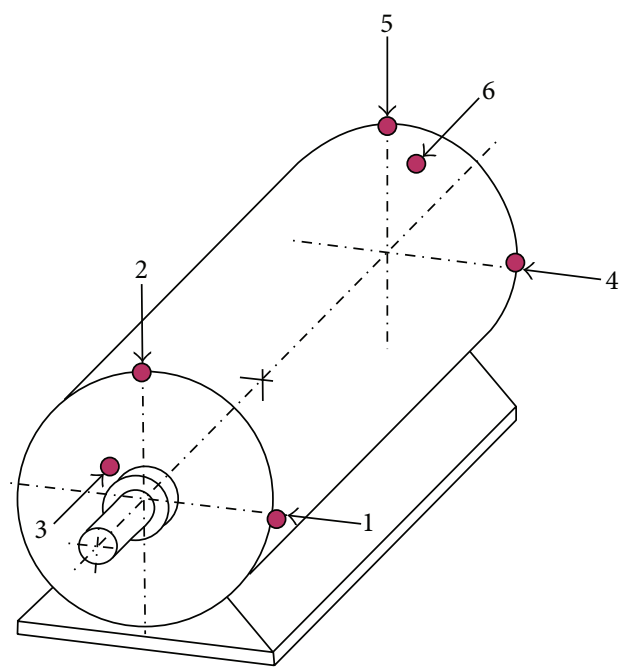

FIGURE 3: ISO 10816 recommended positions for vibration measurements [28], where position-1 and position-4 indicate radialhorizontal directions and position -2 and position -5 indicate radialvertical directions, while position- 3 and position- 6 indicate the axial directions. Position-1, position-2, and position-3 locate nearby the loading side, while position-4, position-5, and position-6 locate nearby the nonloading side.

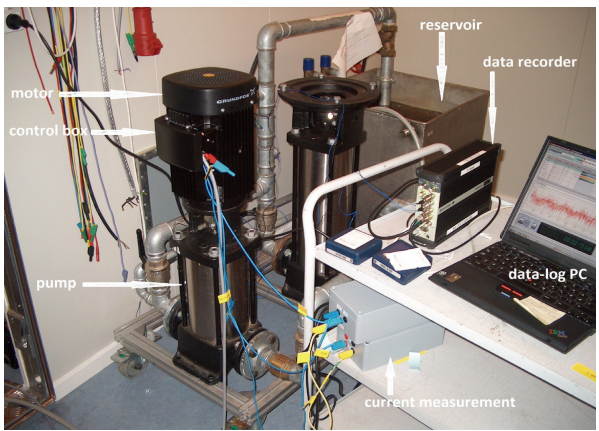

FIGURE 4: The induction motor placed in a water circulation system.

(i) Free load setup: the motor runs freely without any external load and hence no cooling fan inside the housing.

(ii) Fan load setup: the cooling fan is attached on the motor shaft.

(iii) Pump load setup: the motor setup (with cooling fan) is placed in a water circulation system and is used to drive a Grundfos CR- 8 centrifugal pump.

In order to minimize the impact from the surrounding environment on the motor vibration dynamic, the induction motor is suspended on a spring for the first two configurations. The third configuration can be seen in Figure 4.

\section{Experimental Results and Analysis}

A simple bearing condition monitoring can be achieved by checking magnitudes at specific CFs in the spectra, which are 


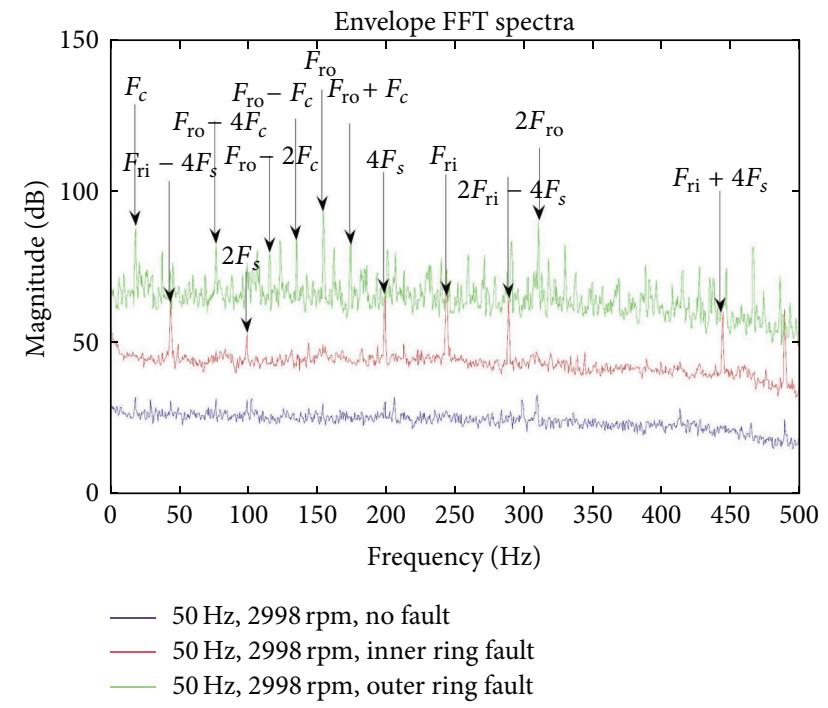

FIGURE 5: Nominal, inner defect, and outer defect spectra of $50 \mathrm{~Hz}$ motor input, free load condition, and radial vibration measurements.

produced based on the measured data. By comparing with a nominal bearing spectrum, if some large amplitude deviations at some specific CFs can be observed, the corresponding fault scenario will be suspected. In this section, we only carry out this intuitive analysis and some systematical and quantitative computation will be proposed in next section. The tests are carried out under different conditions so as to study the influence of different loads, different measuring locations, different rotating speeds, and different sampling segments. The considered motor is controlled by a frequency converter; thereby speeds of the motor are denoted as $50 \mathrm{~Hz}$, $40 \mathrm{~Hz}$, and $20 \mathrm{~Hz}$, respectively. Some selected results are presented in the following.

4.1. Vibration Analysis: Point Defect, Free Load, and Different Shaft Speeds. One set of spectra based on the operating condition with $50 \mathrm{~Hz}$ motor input and radial position measurements is shown in Figure 5. It is quite clear that these three scenarios lead to significantly different averaged amplitude levels. The nominal system curve (blue line) is the most flat one with some small oscillations. There are distinguishable peaks around the inner raceway $\mathrm{CFs}, F_{\mathrm{ri}}$ and $2 F_{\mathrm{ri}}$, on the inner raceway fault curve (red line). Some sideband effects, peaks at frequencies $F_{\mathrm{ri}} \pm 4 F_{s}$ and $2 F_{\mathrm{ri}}-4 F_{s}$, are also clearly observed on the inner raceway fault curve. This is consistent with the statement in [8] that, in case of a defect on a moving element, the spectrum has sidebands about the components at this specific fault CF. The outer raceway fault curve (green line) is the most complicated one. Some distinguishable peaks appear around the outer raceway fault CFs, $F_{\text {ro }}$ and $2 F_{\text {ro }}$. However, there are also a number of distinguishable peaks shown around the cage CF, $F_{c}$ and sidebands of $F_{\text {ro }}$ with $F_{c}$. Therefore, the declaration of outer raceway fault is vague at this moment.

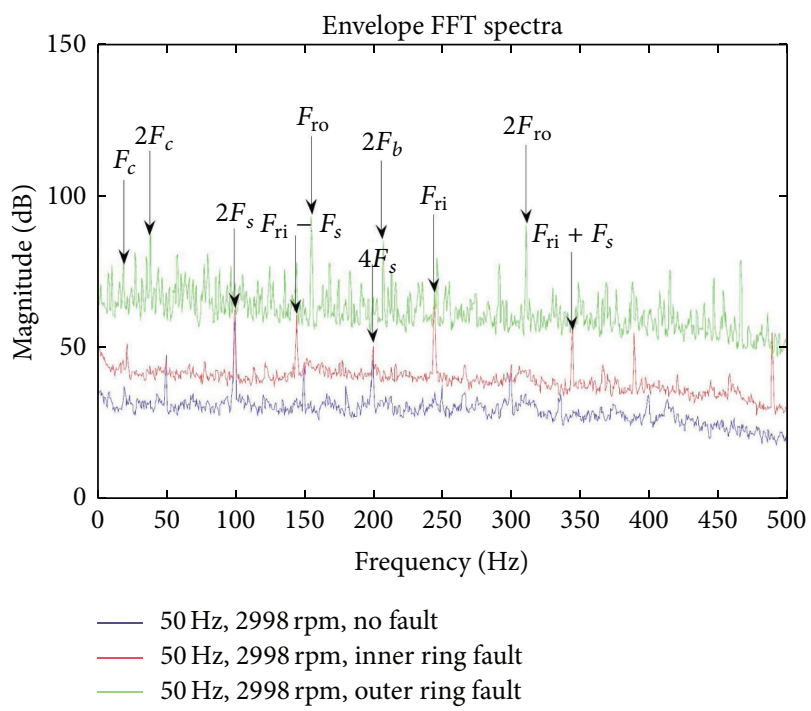

FIGURE 6: Nominal, inner defect, and outer defect spectra of $50 \mathrm{~Hz}$ motor input, free load condition, and axial vibration measurements.

It is also noticed that the measured shaft speed is $2998 \mathrm{rpm}$ which corresponds to $49.97 \mathrm{~Hz}$. There is only $0.06 \%$ speed deviation for this free load case [30]. The CFs calculated through (1), based on this measured speed, are

$$
\begin{aligned}
F_{c} & =19.17 \mathrm{~Hz}, & F_{\mathrm{ri}} & =246.35 \mathrm{~Hz}, \\
F_{\mathrm{ro}} & =153.38 \mathrm{~Hz}, & F_{b} & =101.62 \mathrm{~Hz} .
\end{aligned}
$$

The spectra under the same scenarios but using the axial vibration measurement are illustrated in Figure 6. There are a number of observable differences compared with Figure 5. (1) The average level of the nominal curve is raised up about $5 \mathrm{~dB}$, and some small but distinguishable peaks indicate the rotational speed $F_{s}$ and its harmonies. (2) The inner raceway fault curve shows similar situation as in Figure 5, except that the most distinguished sidebands are now at $F_{\text {ri }} \pm F_{s}$. The outer raceway fault curve becomes slightly better for diagnosis purpose. The two biggest, and also being able to be distinguished from others, are the outer raceway fault $\mathrm{CF}$, $F_{\text {ro }}$, and its harmonic frequency $2 F_{\text {ro }}$. Different measurement locations lead to slight different spectra exhibition that is mainly due to different mechanical transmission paths from the defect to sensors. This can be confirmed through the machine resonance analysis by changing the measurement locations.

The results based on radial vibration measurements under $40 \mathrm{~Hz}$ motor speed are shown in Figure 7. In general, the detection situation is less good than the $50 \mathrm{~Hz}$ situation. The nominal curve starts to indicate the rotating speed and some of its harmonies. There are a number of sidebands of $F_{\text {ri }}$ popping up. No matter how, the indication of an inner raceway fault is still quite clear. The outer curve becomes more distinguishable. The outer raceway fault $\mathrm{CF}, F_{\mathrm{ro}}$, and its harmonic frequency, $2 F_{\text {ro }}$, can be clearly seen and extracted.

The spectra based on the axial measurements under $20 \mathrm{~Hz}$ motor speed are shown in Figure 8. The good thing here is 


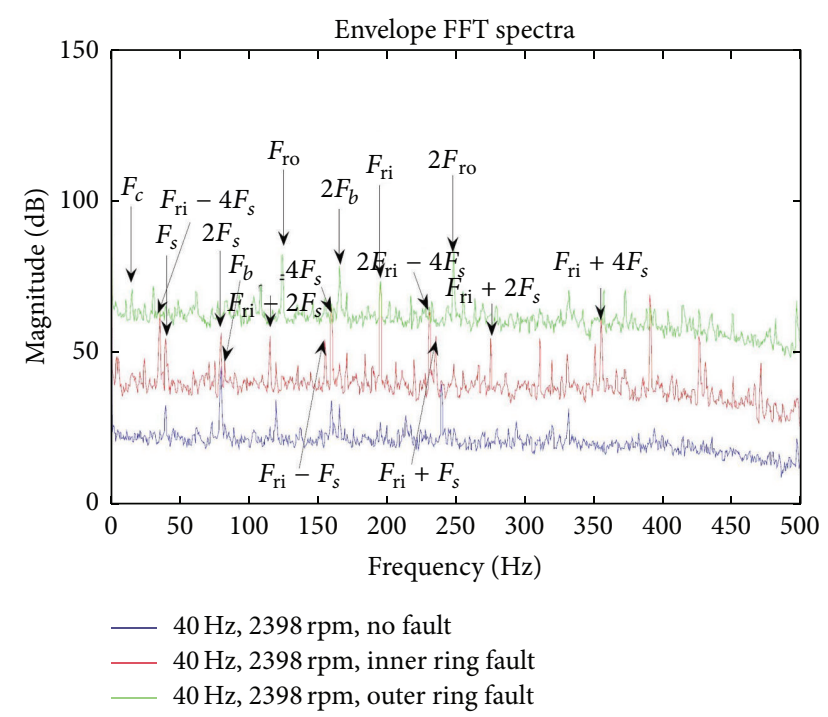

FIGURE 7: Nominal, inner defect, and outer defect spectra of $40 \mathrm{~Hz}$ motor input, free load condition, and radial vibration measurements.

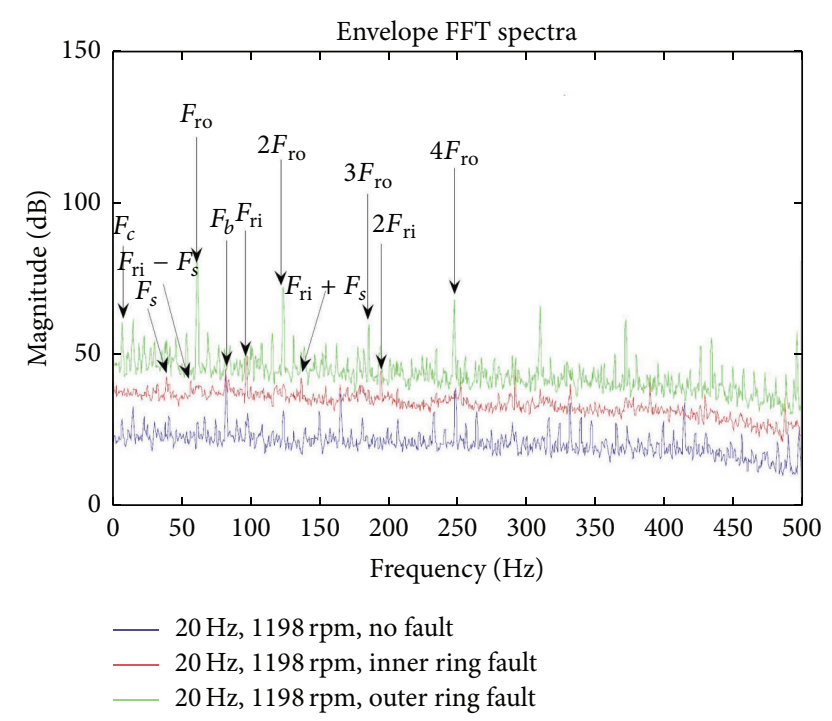

FIGURE 8: Nominal, inner defect, and outer defect spectra of $20 \mathrm{~Hz}$ motor input, free load condition, and axial vibration measurements.

that the outer raceway fault $\mathrm{CF}$ and its harmonies become much more outstanding. On the contrary, there is not nearly any clear indication of inner raceway fault. Meanwhile, the nominal curve becomes more oscillated, which has the risk to give a wrong indication, for example, claiming a ball defect.

It is clear that different motor speeds can lead to significant different spectra features, which could cause the FDD result to deviate from the real case [30]. Fundamentally, different motor speeds cause different excitation signals due to the defect to the machine; thereby the machine response will be naturally different, even though the mechanical transmission path is still the same. Different measurement locations correspond to different mechanical transmission

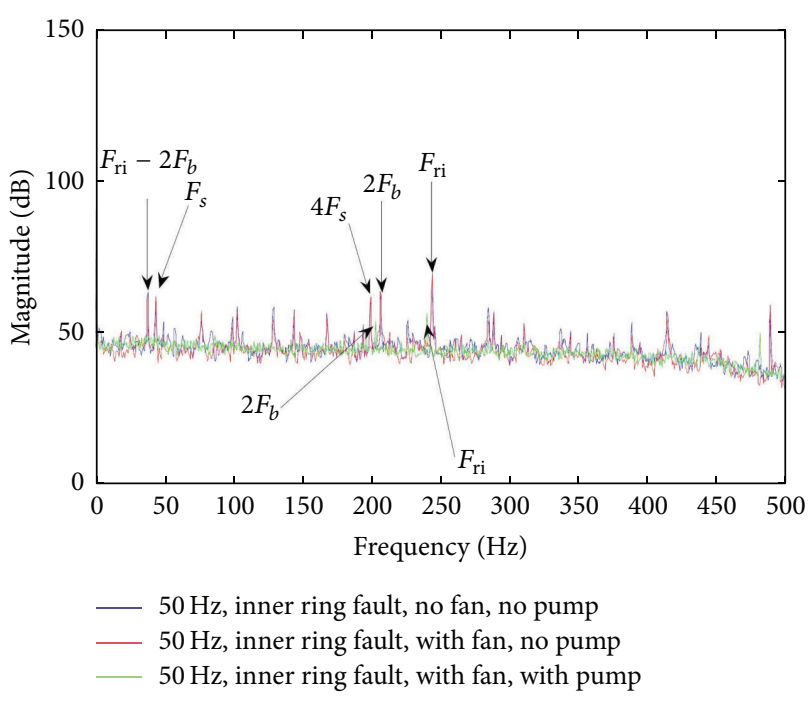

FIGURE 9: Inner defect spectra of $50 \mathrm{~Hz}$ motor input, different load conditions (free load, fan load, and pump load), and radial vibration measurements.

paths. Modeling the mechanical excitation due to the bearing fault at different motor speeds, the mechanic resonance analysis, and modeling of different mechanical transmission paths might help a lot in getting a super feature extraction; however, these issues are much more complicated and sophisticated and thereby beyond this current scope.

4.2. Vibration Analysis: Point Defect, $50 \mathrm{~Hz}$ Input, and Different Load Conditions. Regarding the inner raceway fault, the spectra based on the radial measurements are shown in Figure 9. A quite distinguishable peak appears around the inner fault $\mathrm{CF}, F_{\mathrm{ri}}$, for the free load curve (blue line) and the fan load curve (read line). It should be noticed that a peak at $2 F_{b}$ also shows up on both curves. This can give some puzzle to FDD decision. The spectra of the pump load are different from the other two in terms of having a more flat spectrum with smaller peaks and some small but observable deviations of CFs. The CF's deviations are mainly due to the drift of actual shaft speed, which is measured as $48.96 \mathrm{~Hz}$, while the motor input frequency is $50 \mathrm{~Hz}$. This observation is consistent with [30].

Regarding the outer raceway fault, the spectra based on the radial measurements are shown in Figure 10. There are a lot of oscillations on both curves. However, basically, we still can suspect an outer raceway fault might have happened in this system. It should be noticed that the spectrum with pump load does not suppress peaks much around CFs. This is different from the inner raceway fault situation. This could be mainly due to the centrifugal principle and a multiple-point outer raceway fault as well.

Different load conditions change the machine system's mechanic features, including the resonance features. Even though the mechanic excitation due to the defect is the same, different load conditions lead to different mechanic system features (from the vibration point of view) and naturally different results are observed. The load condition needs to be 


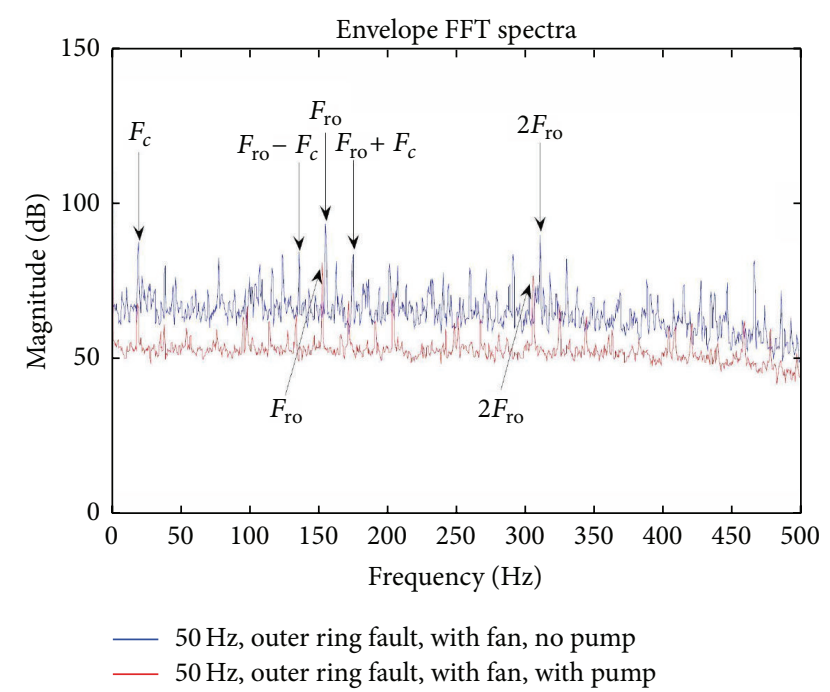

FIGURE 10: Outer defect spectra of $50 \mathrm{~Hz}$ motor input, different load conditions (fan load and pump load), and radial vibration measurements.

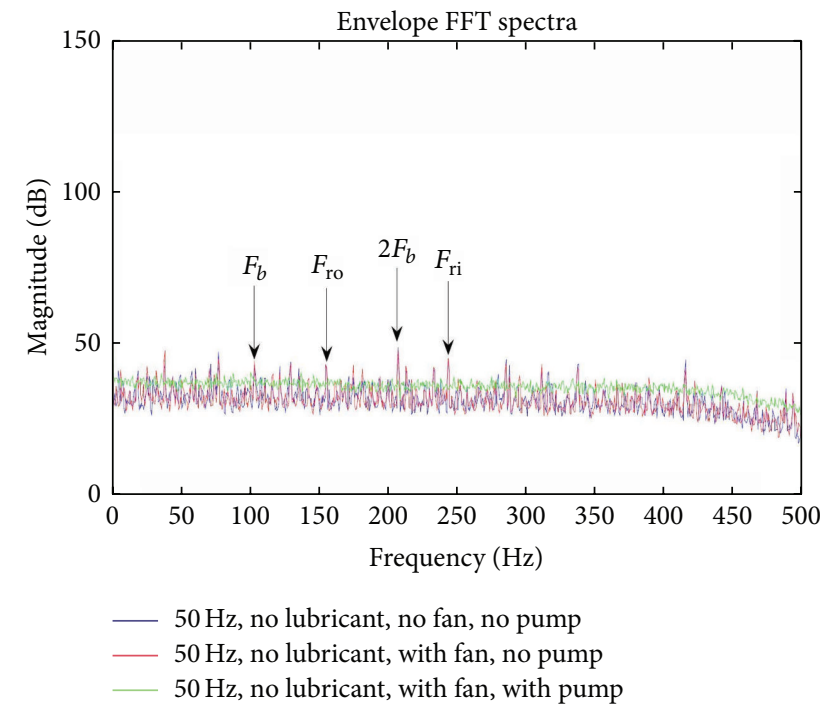

FIGURE 11: Generalized roughness spectra of $50 \mathrm{~Hz}$ motor input, different load conditions (free load, fan load, and pump load), and radial vibration measurements.

coordinated into the model of the considered system in order to obtain consistent results $[7,22]$.

4.3. Vibration Analysis: Generalized Roughness, $50 \mathrm{~Hz}$ Input, and Different Load Conditions. A bearing without lubricant is used to test the FDD analysis under a generalized roughness situation. A set of spectra based on the radial position, $50 \mathrm{~Hz}$ input, and different load conditions is shown in Figure 11. There is little difference between the spectra of free load and fan load conditions. There are some small peaks in these two spectra. However, no peak is over $48 \mathrm{~dB}$. As shown in Figure 5 , the peak for the inner raceway fault can reach $74 \mathrm{~dB}$; therefore, no point defect can be claimed based on

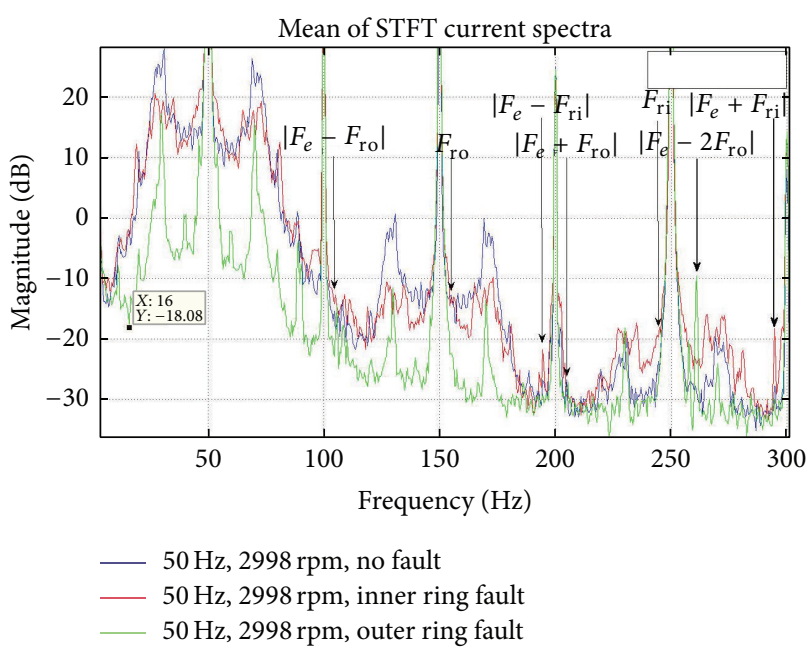

FIgure 12: Nominal, inner defect, and outer defect spectra (0$300 \mathrm{~Hz}$ ) of $50 \mathrm{~Hz}$ motor input, free load condition, and current measurements.

the observation in Figure 11. The spectrum of the pump load is even more flat than the other two.

There seems to be no way we can diagnose these distributed defects by only checking the spectral amplitude in a stationary way. As also mentioned in [8], some other features need to be considered or at least combined along with spectra analysis.

4.4. Current Analysis: Point Defect, Free Load, and $50 \mathrm{~Hz}$ Input. The mean STFT spectrum of a current measurement under the same operational condition as studied in Section 4.1 is shown in Figures 12 and 13, respectively. Both inner and outer fault CCFs can be observed in different ranges. However, the amplitudes of inner raceway fault CCFs quickly vanished with the increased frequency, whereas the amplitudes corresponding to outer raceway fault become more distinguished for the high-frequency range. It is noticed that the power supply frequency $(50 \mathrm{~Hz})$ and its harmonies are dominant in this spectrum; they are disturbing the intuitive judgement. One possible way to avoid this problem is to use the shaft angle as a progression variable in place of the time; then some angular position transmitter is required. Alternatively, some quantitative evaluation is required in order to get a reliable decision $[13,22,26]$. This issue is studied in the next section.

4.5. Current Analysis: Point Defect, $50 \mathrm{~Hz}$ Input, and Different Load Conditions. The mean STFT spectrum of a current measurement with frequency range as $300-600 \mathrm{~Hz}$, under the same operational conditions as studied in Section 4.2, is shown in Figure 14. Intuitively, It seems hard to detect the inner raceway fault from the free load and fan load curves (due to the dominant peaks' disturbance). However, it is quite clear that the inner raceway fault CCFs appear significantly in the pump load spectrum; we can easily suspect this type of 


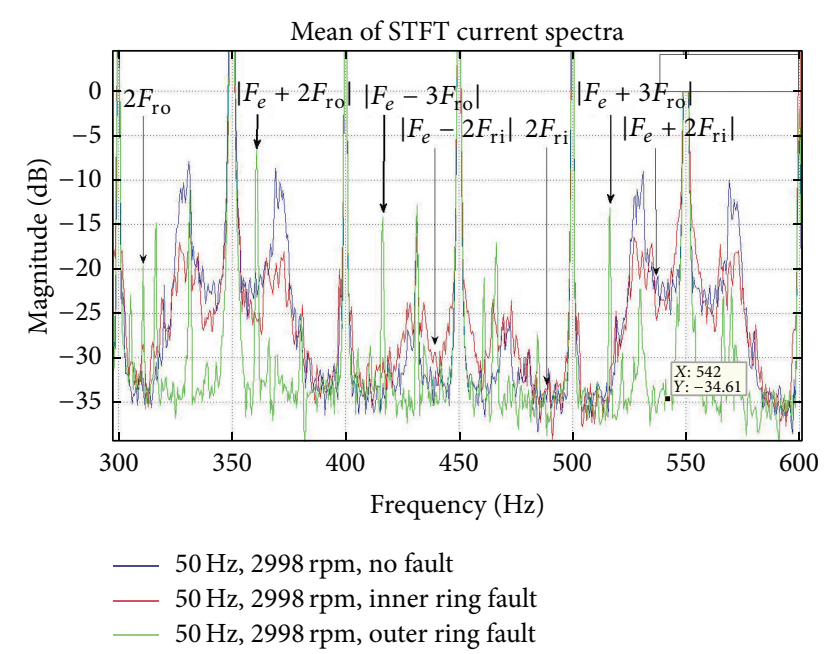

FIGURE 13: Nominal, inner defect, and outer defect spectra (300$600 \mathrm{~Hz}$ ) of $50 \mathrm{~Hz}$ motor input, free load condition, and current measurements.

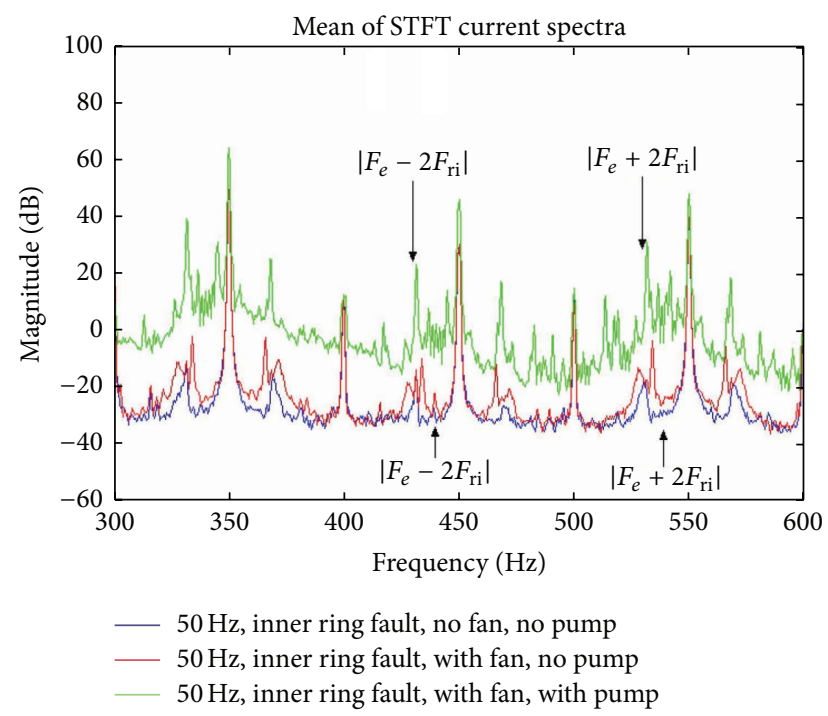

FIGURE 14: Inner defect spectra of $50 \mathrm{~Hz}$ motor input, different load conditions, and current measurements.

fault under this kind of load condition. For other two cases, some dedicated quantitative evaluation is required.

4.6. Temporal Feature Analysis: Generalized Roughness, $50 \mathrm{~Hz}$ Input, and Pump Load Setup. Similar to the vibration analysis, the generalized roughness can not be detected by the current signature analysis no matter under what kind of motor speeds or loading configurations. However, by using a set of data sampled from different running time segments, this kind of fault can be indicated by checking the temporal features of frequency analysis. A study of the no-lubricant fault with $50 \mathrm{~Hz}$ input, pump load configuration, and vibration measurement is shown in Figure 15. The temporal development of this type of fault can be clearly observed.

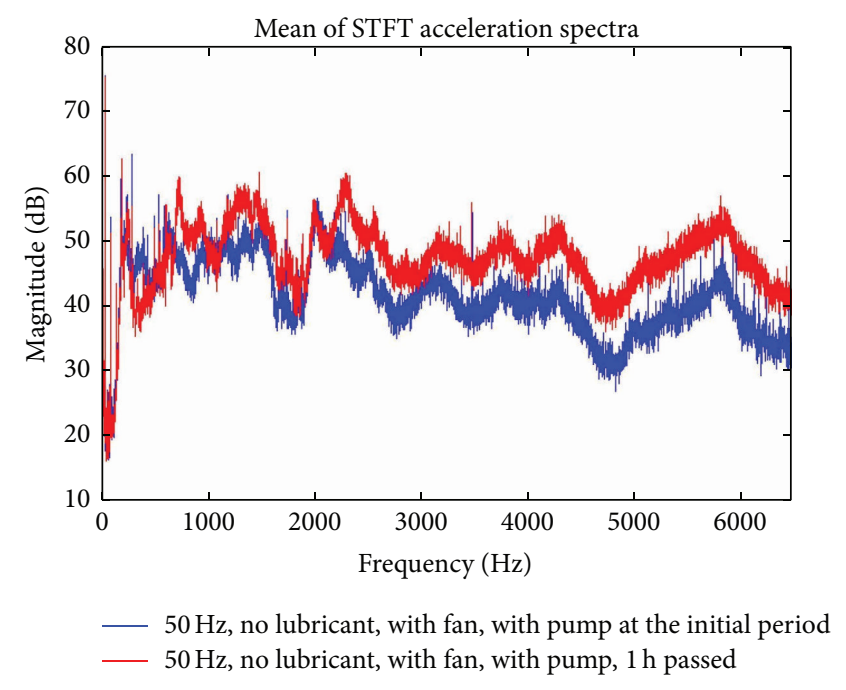

FIGURE 15: Generalized roughness spectra of $50 \mathrm{~Hz}$ motor input, the pump load condition, radial vibration measurements, and sample segments with one-hour interval.

TABLE 1: Statistical evaluation of vibration measurements.

\begin{tabular}{lcccc}
\hline Scenario & Mean & Variance & MD (\%) & VD (\%) \\
\hline $50 \mathrm{~Hz}$, Nom & 0.3473 & 0.0846 & & \\
$50 \mathrm{~Hz}$, Inner & 0.3478 & 3.1295 & 0.14 & $3.599 \times 10^{3}$ \\
$50 \mathrm{~Hz}$, Outer & 0.3482 & 873.7352 & 0.26 & $1.033 \times 10^{6}$ \\
$50 \mathrm{~Hz}$, Lub. & 0.3775 & 0.2715 & 0.87 & $2.2092 \times 10^{2}$ \\
\hline $40 \mathrm{~Hz}$, Nom & 0.3474 & 0.0597 & & \\
$40 \mathrm{~Hz}$, Inner & 0.3484 & 2.0753 & 0.29 & $3.376 \times 10^{3}$ \\
$40 \mathrm{~Hz}$, Outer & 0.3483 & 303.3030 & 0.26 & $5.08 \times 10^{5}$ \\
\hline $20 \mathrm{~Hz}$, Nom & 0.3487 & 0.0116 & & \\
$20 \mathrm{~Hz}$, Inner & 0.3483 & 0.3039 & -0.11 & $2.520 \times 10^{3}$ \\
$20 \mathrm{~Hz}$, Outer & 0.3488 & 13.3662 & 0.01 & $1.150 \times 10^{5}$ \\
\hline
\end{tabular}

\section{An Automatic Monitoring System}

A simple automatic monitoring system for bearing FDD is proposed and discussed in the following.

5.1. Vibration Based Fault Detection. If the vibration measurement is available, the fault detection can be carried out simply using the statistic features of the vibration data. For example, the statistical features of pieces of vibration measurements are summarized in Table 1, where "MD/VD" means deviation of the mean/variance with respect to the corresponding nominal mean/variance, evaluated in terms of percentage. It can be seen that different fault scenarios do not cause much deviations of mean values, but the deviations of variances are quite significant. Thereby, the considered three types of fault scenarios can be easily detected by checking the variance of the measured vibration signal; for example, if the VD is over $100 \%$, we can claim that some bearing fault occurred in the system (under assumption that other system 
parts are healthy). Of course, the RMS, crest factor, or kurtosis [3] can also be used for detection purpose.

Unfortunately, we observed that the statistical analysis of the current measurement is not as good as the vibration analysis. However, the current based fault detection can be combined with the current based fault diagnosis procedure, which is discussed in the following.

5.2. Vibration and Current Fault Indices. In order to develop an automatic health monitoring system, some quantitative indices and criteria need to be set up before proposing any computation algorithm. In the following, two types of relative spectral amplitudes are defined with respect to vibration and current analysis, respectively.

A vibration fault index (VFI) is defined as a function of the frequency on the vibration envelope spectrum as

$$
V\left(f_{i}\right)=\frac{A^{v}\left(f_{i}\right)-\operatorname{average}^{v}\left(f_{1}, f_{2}\right)}{\operatorname{average}^{v}\left(f_{1}, f_{2}\right)} \times 100 \%,
$$

where $A^{v}\left(f_{i}\right)$ is the spectral amplitude at specific characteristic frequency $f_{i}$. average ${ }^{v}\left(f_{1}, f_{2}\right)$ is the average amplitude value of the considered spectrum within frequency interval $\left[f_{1}, f_{2}\right]$, and it can be calculated by

$$
\operatorname{average}^{v}\left(f_{1}, f_{2}\right)=\frac{\int_{f_{1}}^{f_{2}} A^{v}(f) d f}{f_{2}-f_{1}} .
$$

Usually, there is $f_{i} \in\left[f_{1}, f_{2}\right]$. The VFI is a type of relative amplitude deviation, that is, a peak-to-average ratio [29].

A current fault index (CFI) is defined as a function of the frequency on the mean STFT (3) of current as

$$
C\left(f_{i}\right) \hat{=} \frac{A^{c}\left(f_{i}\right)-A_{n}^{c}\left(f_{i}\right)}{A_{n}^{c}\left(f_{i}\right)} \times 100 \%,
$$

where $A^{c}\left(f_{i}\right)$ is the spectral amplitude at a specific current characteristic frequency $f_{i}$ on the concerned current spectrum, and $A_{n}^{c}\left(f_{i}\right)$ is the spectral amplitude at the corresponding frequency $f_{i}$ on the nominal current spectrum. Thereby, this nominal spectrum needs to be obtained beforehand when we are sure that the considered bearing is healthy. CFI is a type of peak-to-peak ratio but defined on two different spectra (nominal one and underchecked one) produced under the same operating condition.

5.3. CF/CCF Deviations and CF/CCF Neighborhoods. As we discussed in the previous section, there are some deviations between the measured CFs and calculated ones; this issue could be due to the slipping or sliding motions. Some observed deviations are summarized in Table 2, where "C" represents the calculated CF using (1), " $M$ " represents the measured one, and " $\mathrm{D}(\%)$ " indicates the deviation of the measured CF from the calculated one in terms of percentage.

The motivation for doing this is that, practically, when the spectral amplitudes at CFs or CCFs need to be checked, we need to keep in mind that the practical characteristic
TABLE 2: Deviations (percentage) of measured and calculated CFs at $20 \mathrm{~Hz}$ and $50 \mathrm{~Hz}$ motor inputs and free load condition.

\begin{tabular}{ccc}
\hline Scenarios & $50 \mathrm{~Hz}$ input & $20 \mathrm{~Hz}$ input \\
\hline Cage & & \\
C & 19.18 & 7.67 \\
M & 19.5 & 8.0 \\
D (\%) & $\mathbf{1 . 6 7}$ & $\mathbf{4 . 3}$ \\
Ball & & \\
C & 101.68 & 40.67 \\
M & 103.5 & 41.5 \\
D (\%) & $\mathbf{1 . 7 9}$ & $\mathbf{2 . 0 4}$ \\
Inner & & \\
C & 246.51 & 98.60 \\
M & 244.5 & 97.5 \\
D (\%) & $-\mathbf{0 . 8 2}$ & $-\mathbf{1 . 1 2}$ \\
Outer & & \\
C & 153.49 & 61.39 \\
M & 155.5 & 62.0 \\
D (\%) & $\mathbf{1 . 3 2}$ & $\mathbf{0 . 9 9}$ \\
\hline
\end{tabular}

frequencies might have some drift from the theoretical ones besides the frequency resolution issue. How much drift needs to be considered is determined by this CF deviation analysis. As shown in Table 2, the largest value under this operation condition is $4.3 \%$. Furthermore, as we have observed in previous section, the different load conditions can also cause the rotating speed deviated from the assumed one (e.g., according to power supply frequency). For instance, when the power supply is at $50 \mathrm{~Hz}$ to the pump loaded motor, the measured motor speed is actually at $48.96 \mathrm{~Hz}$. There is $2.08 \%$ deviation regarding the converter frequency. Thereby, considering the spectral amplitude within a frequency vicinity centralized at one specific CF or CCF would be more reasonable than just considering one specific frequency. Thereby, a neighborhood of a specific CF or CCF is defined in the following.

A neighborhood of a specific CF or CCF, defined as a frequency interval centralized at $\mathrm{CF}$ (or CCF), $f_{\mathrm{cf}}$, is denoted as

$$
\Delta\left(f_{i}\right) \hat{=}\left[f_{i}-\delta_{i}, f_{i}+\delta_{i}\right],
$$

where the tolerance range $\delta_{i}$ can be determined according to the above CF deviation analysis.

5.4. Fault Detection and Diagnosis Scheme. Once the neighborhood tolerance $\delta_{i}$ of relevant CF or CCFs is defined, the fault diagnosis can be committed by using the defined VFI for vibration analysis and CFI for current analysis, respectively. The procedure is briefed in the following.

(1) Determine all $\mathrm{CFs} / \mathrm{CCF}$ s and possibly their harmonies as well as neighborhoods within a considered frequency range. 
TABLE 3: Calculated $V^{\Delta}\left(f_{i}\right)$ s within $[0,500 \mathrm{~Hz}], 50 \mathrm{~Hz}$ motor input, free load condition, and radial vibration measurements.

\begin{tabular}{lccc}
\hline $\mathrm{CF}(\mathrm{Hz} \pm 2 \%)$ & No fault $(\%)$ & Inner $(\%)$ & Outer $(\%)$ \\
\hline$F_{b}: 101.68$ & 23.90 & 2.22 & 5.97 \\
$F_{\mathrm{ro}}: 153.49$ & 21.18 & 11.11 & $\mathbf{4 1 . 7 9}$ \\
$2 F_{b}: 203.36$ & 27.88 & 6.67 & 22.39 \\
$F_{\mathrm{ri}}: 246.51$ & 14.8 & $\mathbf{5 1 . 1 1}$ & 13.43 \\
$3 F_{b}: 305.04$ & 27.6 & 4.44 & 4.48 \\
$2 F_{\mathrm{ro}}: 306.98$ & $\mathbf{3 2 . 4}$ & 8.89 & $\mathbf{4 0 . 3 0}$ \\
$4 F_{b}: 406.72$ & -14.00 & -2.21 & 8.96 \\
$3 F_{\mathrm{ro}}: 460.47$ & -20.00 & -1.18 & 20.90 \\
$2 F_{\mathrm{ri}}: 493.02$ & 0.10 & $\mathbf{4 2 . 2 2}$ & -11.94 \\
\hline
\end{tabular}

(2) Find out the $\Delta$-neighborhood VFI, denoted as $V^{\Delta}\left(f_{i}\right)$, for each considered (vibration) characteristic frequency, which is defined based on (6) as

$$
V^{\Delta}\left(f_{i}\right) \hat{=} \max _{f \in \Delta\left(f_{i}\right)} V(f)
$$

Similarly, in case of the current analysis, the $\Delta$ neighborhood CFI, denoted as $C^{\Delta}\left(f_{i}\right)$, can be defined based on (8) as

$$
C^{\Delta}\left(f_{i}\right)=\frac{A^{c}\left(f_{m}\right)-A_{n}^{c}\left(f_{m_{n}}\right)}{A_{n}^{c}\left(f_{m_{n}}\right)} \times 100 \%,
$$

with the parameters

$$
\begin{gathered}
f_{m}=\arg \max _{f \in \Delta\left(f_{i}\right)} A^{c}(f), \\
f_{m_{n}}=\arg \max _{f \in \Delta\left(f_{i}\right)} A_{n}^{c}(f) .
\end{gathered}
$$

(3) List all results in a table and examine CF consistency of the results. If most values corresponding to one specific fault scenario's CF/CCFs (and possibly their harmonies as well) are significantly larger than any other scenarios, then declare this fault scenario.

(4) If necessary, the amplitudes at sidebands frequency neighborhoods also need to be checked.

By following this scheme, the vibration analysis regarding the operation with $50 \mathrm{~Hz}$ motor speed and free load (data is shown in Figure 5) is summarized in Table 3. It can be noticed that both inner and outer raceway spectra have two VFI values above $40 \%$ at their CFs and double CFs, respectively. Meanwhile, at these frequencies of the other scenarios, the values are significantly small. There could be a risk to declare the nominal bearing as with an outer raceway fault if we set up the threshold as $30 \%$. However, this false declaration is clearly conflicted with the variance analysis listed in Table 1. Thereby, we can see that the different faulty bearings can be safely distinguished for this data.

The vibration FDD analysis regarding the operation with $20 \mathrm{~Hz}$ motor speed and free load (data is shown in Figure 8)
TABLE 4: Calculated $V^{\Delta}\left(f_{i}\right)$ s within $[0,310 \mathrm{~Hz}], 20 \mathrm{~Hz}$ motor input, free load condition, and axial vibration measurements.

\begin{tabular}{lccc}
\hline $\mathrm{CF}(\mathrm{Hz} \pm 1.5 \%)$ & No fault $(\%)$ & Inner $(\%)$ & Outer $(\%)$ \\
\hline$F_{b}: 40.67$ & 18.75 & 8.33 & 9.52 \\
$F_{\mathrm{ro}}: 61.39$ & 18.12 & 11.11 & $\mathbf{8 0 . 9 5}$ \\
$2 F_{b}: 81.34$ & $\mathbf{1 0 0 . 6 3}$ & 30.56 & 20.24 \\
$F_{\mathrm{ri}}: 98.60$ & $\mathbf{8 7 . 5 0}$ & $\mathbf{4 4 . 4 4}$ & 23.81 \\
$3 F_{b} / 2 F_{\mathrm{ro}}: 122.01 / 122.78$ & 23.75 & 15.28 & $\mathbf{6 6 . 6 7}$ \\
$4 F_{b}: 162.68$ & 5.10 & 6.94 & 7.14 \\
$3 F_{\mathrm{ro}}: 184.17$ & 1.20 & 9.72 & 35.71 \\
$2 F_{\mathrm{ri}}: 197.20$ & -1.15 & $\mathbf{3 6 . 1 1}$ & 11.90 \\
$5 F_{b}: 203.35$ & 1.16 & 10.56 & 7.11 \\
$6 F_{b} / 4 F_{\mathrm{ro}}: 244.02 / 245.56$ & 37.5 & 17.22 & $\mathbf{4 5 . 2 4}$ \\
$3 F_{\mathrm{ri}}: 295.80$ & 18.75 & 20.83 & 16.67 \\
$5 F_{\mathrm{ro}}: 306.95$ & 4.60 & 9.12 & $\mathbf{5 1 . 0 1}$ \\
\hline
\end{tabular}

TABLE 5: Calculated $C^{\Delta}\left(f_{i}\right)$ s within $[0,540] \mathrm{Hz}, 50 \mathrm{~Hz}$ motor input, free load condition, and current measurements.

\begin{tabular}{lcc}
\hline $\mathrm{CCF}(\mathrm{Hz} \pm 2 \%)$ & Inner $(\%)$ & Outer $(\%)$ \\
\hline$\left|F_{e}-F_{\mathrm{ro}}\right|: 105.5$ & 17.26 & 10.10 \\
$F_{\mathrm{ro}}: 155.4$ & -9.62 & -70.50 \\
$\left|F_{e}-F_{\mathrm{ri}}\right|: 194.4$ & 21.90 & -7.90 \\
$\left|F_{e}+F_{\mathrm{ro}}\right|: 205.4$ & 10.54 & -5.11 \\
$\left|F_{e}-2 F_{\mathrm{ro}}\right|: 260.9$ & 18.75 & $\mathbf{6 6 . 9 0}$ \\
$\left|F_{e}+F_{\mathrm{ri}}\right|: 294.3$ & $\mathbf{3 4 . 3 2}$ & -7.82 \\
$\left|F_{e}+2 F_{\mathrm{ro}}\right|: 360.8$ & -20.73 & $\mathbf{6 8 . 1 5}$ \\
$\left|F_{e}-3 F_{\mathrm{ro}}\right|: 416.3$ & 8.80 & $\mathbf{5 6 . 9 0}$ \\
$\left|F_{e}-2 F_{\mathrm{ri}}\right|: 438.7$ & 15.5 & -8.51 \\
$\left|F_{e}+3 F_{\mathrm{ro}}\right|: 516.3$ & 12.23 & $\mathbf{5 7 . 6 1}$ \\
$\left|F_{e}+2 F_{\mathrm{ri}}\right|: 538.6$ & 11.11 & -71.8 \\
\hline
\end{tabular}

is summarized in Table 4. It can be noticed that the outer raceway fault can be easily distinguished from other fault scenarios: there are four values over $45 \%$. The inner race fault can also be moderately distinguished by checking the $\mathrm{CF}$ consistency of the two biggest values. There can be a trouble regarding the nominal bearing. However, a number of observations could help minimize the risk. (1) There is not any CF consistency among values over $40 \%$. (2) The statistical evaluation is preferred to be a nominal bearing. (3) If possible, speed up the motor to $50 \mathrm{~Hz}$ and then generate Table 3 for diagnosis.

The current FDD analysis based on the data shown in Figures 12 and 13 is summarized in Table 5. It can be noticed that the outer raceway fault can be easily distinguished from others. The diagnosis of inner raceway fault can be a little bit tough, even though the two biggest values consistently indicate an inner defect bearing. The differences of all values are not significantly large. This is partially due to the fact that the inner raceway fault is just a tiny scratch on the surface, and another reason could be due to the fact that normally the inner raceway fault is more difficult to be diagnosed [7]. 


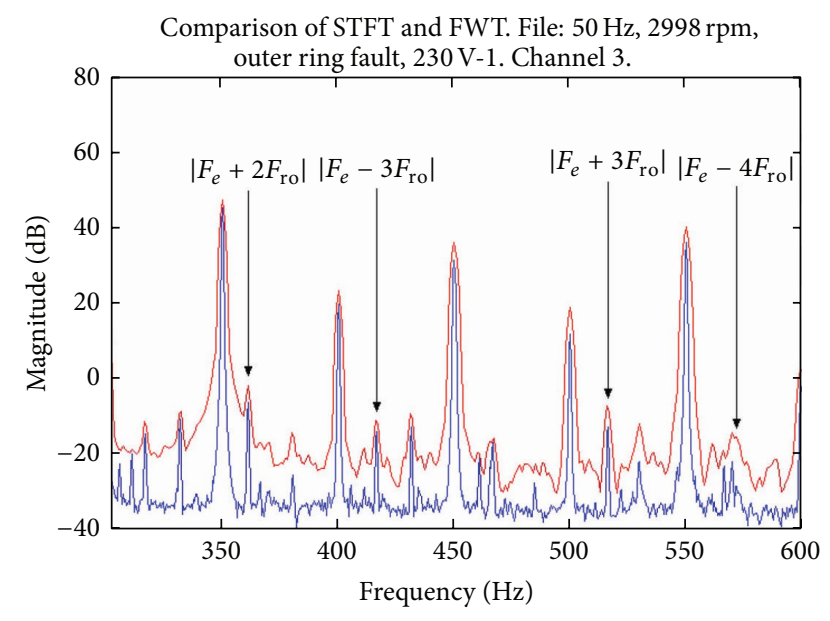

_ Mean of STFT current spectra

_ Mean of FWT current spectra

FIGURE 16: Comparison of FWT and STFT current analysis for $50 \mathrm{~Hz}$ input, pump load, outer raceway fault, and current measurement.

\section{Discussion and Conclusion}

In general, the vibration based analysis showed a significant power in detection and diagnosis of bearing point defects. The current based analysis also did give better results than we thought before, even though it could not achieve as good results as vibration analysis for some situations. Among all the designed scenarios, the outer raceway fault can be detected for different motor speeds and different load conditions, whether using the vibration analysis or using the current analysis. The inner raceway fault can be clearly detected for the pump load condition whatever the methods used. Some temporal features of bearing faults and their influences on FDD analysis are also investigated in this work. For instance, some different peaks showed up in the demodulated vibration spectra corresponding to data obtained from different time segments. Meanwhile, no much difference is visible in the current spectra.

Apparently, the FDD thresholds for the proposed analysis and approach are empirically determined. By considering the statistical confidence of false alarm and miss probabilities, to systematically determine a quantitative threshold for a specific fault scenario subject to different operating conditions as well as configurations needs to be further investigated.

A preliminary study using the fast wavelet transform (FWT) is also investigated. A comparison of the current analysis using STFT and FWT for outer raceway fault, $50 \mathrm{~Hz}$ input, and pump load is shown in Figure 16. In this case, the FWT does not show a good performance as STFT does. Meanwhile it requires much more computation resource. Of course, here we only consider the stationary situation. We believe the FWT technique will perform much better in case of coping with nonstationary situation.

The condition monitoring for a class of rolling-element bearings is studied, using both vibration based methods and stator current based methods. Three typical types of bearing faults are considered, namely, single-point defect, multiplepoint defects, and a type of generalized roughness. The FDD performance is examined under diverse conditions: with respect to sensor locations, speeds, loading conditions, and temporal samples. The high-frequency resonance technique with envelope detection is used for vibration analysis, and the mean magnitude of STFT is used for the current analysis. A simple automatic FDD system is proposed after defining a number of simple fault indexes. The experimental results showed the super capability of vibration analysis under the stationary operation. The current based analysis also showed a moderate capability in diagnosis of point defect faults. The generalized roughness fault can not be directly detected by these proposed methods. However, the temporal feature analysis indicated some feasibility to detect this kind of fault. This work shows a huge potential to use some onshelf methods for successful diagnosis of industrial bearing systems.

Of course, for a complex mechanical system, there might be some more severe problems than the bearing faults, such as the vibration overrun problem. Nevertheless, a good bearing condition monitoring system could helpfully provide necessary information to distinguish different fault resources in a complex system at an early stage. Furthermore, if the phase current analysis can be implemented and integrated into an already existing motor control system, the early FDD due to bearing problems could also be naturally committed by the same control system, without requiring installation of any extra hardware.

\section{Conflict of Interests}

The author declares that there is no conflict of interests regarding the publication of this paper.

\section{Acknowledgments}

The author thanks former students Uffe C. Merrild and Morten T. Runge for committing most of experimental tests and also thanks Dr. H. Børsting from Grundfos Management A/S for providing some technical facilities and supports.

\section{References}

[1] O. V. Thorsen and M. Dalva, "Survey of faults on induction motors in offshore oil industry, petrochemical industry, gas terminals, and oil refineries," IEEE Transactions on Industry Applications, vol. 31, no. 5, pp. 1186-1196, 1995.

[2] M. Muenchhof, M. Beck, and R. Isermann, "Fault-tolerant actuators and drives-structures, fault detection principles and applications," Annual Reviews in Control, vol. 33, no. 2, pp. 136148, 2009.

[3] R. Isermann, Fault-Diagnosis Systems-An Introduction from Fault Detection to Fault Tolerance, Springer, Berlin, Germany, 2006.

[4] P. Zhang, Y. Du, T. G. Habetler, and B. Lu, "A survey of condition monitoring and protection methods for medium-voltage induction motors," IEEE Transactions on Industry Applications, vol. 47, no. 1, pp. 34-46, 2011. 
[5] M. Lebold, K. McClintic, and R. Campbell, "Review of vibration analysis methods for gearbox diagnostics and prognostics," in Proceedings of the 54th Meeting of the Society for Machinery Failure Prevention Technology, pp. 623-634, Virginia Beach, Va, USA, May 2000.

[6] S. Nandi, H. A. Toliyat, and X. Li, "Condition monitoring and fault diagnosis of electrical motors-a review," IEEE Transactions on Energy Conversion, vol. 20, no. 4, pp. 719-729, 2005.

[7] J. R. Stack, T. G. Habetler, and R. G. Harley, "Fault-signature modeling and detection of inner-race bearing faults," IEEE Transactions on Industry Applications, vol. 42, no. 1, pp. 61-68, 2006.

[8] N. Tandon and A. Choudhury, "A review of vibration and acoustic measurement methods for the detection of defects in rolling element bearings," Tribology International, vol. 32, no. 8, pp. 469-480, 1999.

[9] P. D. McFadden and J. D. Smith, "Model for the vibration produced by a single point defect in a rolling element bearing," Journal of Sound and Vibration, vol. 96, no. 1, pp. 69-82, 1984.

[10] J. R. Stack, T. G. Habeter, and R. G. Harley, "Fault classification and fault signature production for rolling element bearings in electric machines," IEEE Transactions on Industry Applications, vol. 40, no. 3, pp. 735-739, 2004.

[11] P. D. McFadden and J. D. Smith, "The vibration produced by multiple point defects in a rolling element bearing," Journal of Sound and Vibration, vol. 98, no. 2, pp. 263-273, 1985.

[12] A. Bellini, F. Filippetti, C. Tassoni, and G.-A. Capolino, "Advances in diagnostic techniques for induction machines," IEEE Transactions on Industrial Electronics, vol. 55, no. 12, pp. 4109-4126, 2008.

[13] M. E. H. Benbouzid, "A review of induction motors signature analysis as a medium for faults detection," IEEE Transactions on Industrial Electronics, vol. 47, no. 5, pp. 984-993, 2000.

[14] P. D. McFadden and J. D. Smith, "Vibration monitoring of rolling element bearings by the high-frequency resonance technique-a review," Tribology International, vol. 17, no. 1, pp. 3-10, 1984.

[15] R. B. Randall and J. Antoni, "Rolling element bearing diagnostics-A tutorial," Mechanical Systems and Signal Processing, vol. 25, no. 2, pp. 485-520, 2011.

[16] C. Bianchini, F. Immovilli, M. Cocconcelli, R. Rubini, and A. Bellini, "Fault detection of linear bearings in brushless AC linear motors by vibration analysis," IEEE Transactions on Industrial Electronics, vol. 58, no. 5, pp. 1684-1694, 2011.

[17] D. He, R. Li, and J. Zhu, "Plastic bearing fault diagnosis based on a two-step data mining approach," IEEE Transactions on Industrial Electronics, vol. 60, no. 8, pp. 3429-3440, 2013.

[18] M. E. H. Benbouzid and G. B. Kliman, "What stator current processing-based technique to use for induction motor rotor faults diagnosis?" IEEE Transactions on Energy Conversion, vol. 18, no. 2, pp. 238-244, 2003.

[19] X. Gong and W. Qiao, "Bearing fault diagnosis for directdrive wind turbines via current-demodulated signals," IEEE Transactions on Industrial Electronics, vol. 60, no. 8, pp. 34193428, 2013.

[20] S. A. McInerny and Y. Dai, "Basic vibration signal processing for bearing fault detection," IEEE Transactions on Education, vol. 46, no. 1, pp. 149-156, 2003.

[21] B. Li, M.-Y. Chow, Y. Tipsuwan, and J. C. Hung, "Neuralnetwork-based motor rolling bearing fault diagnosis," IEEE Transactions on Industrial Electronics, vol. 47, no. 5, pp. 10601069, 2000.
[22] M. Blödt, P. Granjon, B. Raison, and G. Rostaing, "Models for bearing damage detection in induction motors using stator current monitoring," IEEE Transactions on Industrial Electronics, vol. 55, no. 4, pp. 1813-1822, 2008.

[23] F. Immovilli, C. Bianchini, M. Cocconcelli, A. Bellini, and R. Rubini, "Bearing fault model for induction motor with externally induced vibration," IEEE Transactions on Industrial Electronics, vol. 60, no. 8, pp. 3408-3418, 2013.

[24] L. Eren and M. J. Devaney, "Bearing damage detection via wavelet packet decomposition of the stator current," IEEE Transactions on Instrumentation and Measurement, vol. 53, no. 2, pp. 431-436, 2004.

[25] P. W. Tse, Y. H. Peng, and R. Yam, "Wavelet analysis and envelope detection for rolling element bearing fault diagnosistheir effectiveness and flexibilities," Journal of Vibration and Acoustics, vol. 123, no. 3, pp. 303-310, 2001.

[26] B. Yazici and G. B. Kliman, "An adaptive statistical timefrequency method for detection of broken bars and bearing faults in motors using stator current," IEEE Transactions on Industry Applications, vol. 35, no. 2, pp. 442-452, 1999.

[27] Z. Yang, U. C. Merrild, M. T. Runge, G. Pedersen, and H. Børsting, "A study of rolling-element bearing fault diagnosis using motor's vibration and current signatures," in Proceedings of the 7th IFAC International Symposium on Fault Detection, Supervision and Safety of Technical Systems, (SAFEPROCESS '09), pp. 354-359, Barcelona, Spain, July 2009.

[28] ISO, "Mechanical vibration-evaluation of machine vibration by measurements on non-rotating parts-part one: general guidelines," Tech. Rep. 10816-1:1995, ISO, 1995.

[29] J. R. Stack, R. G. Harley, and T. G. Habetler, "An amplitude modulation detector for fault diagnosis in rolling element bearings," IEEE Transactions on Industrial Electronics, vol. 51, no. 5, pp. 1097-1102, 2004.

[30] J. R. Stack, T. G. Habetler, and R. G. Harley, "Effects of machine speed on the development and detection of rolling element bearing faults," IEEE Power Electronics Letters, vol. 1, no. 1, pp. 19-21, 2003.

[31] R. R. Schoen, T. G. Habetler, F. Kamran, and R. G. Bartheld, "Motor bearing damage detection using stator current monitoring," IEEE Transactions on Industry Applications, vol. 31, no. 6, pp. 1274-1279, 1995.

[32] L. Frosini and E. Bassi, "Stator current and motor efficiency as indicators for different types of bearing faults in induction motors," IEEE Transactions on Industrial Electronics, vol. 57, no. 1, pp. 244-251, 2010.

[33] F. Immovilli, A. Bellini, R. Rubini, and C. Tassoni, "Diagnosis of bearing faults in induction machines by vibration or current signals: a critical comparison," IEEE Transactions on Industry Applications, vol. 46, no. 4, pp. 1350-1359, 2010.

[34] U. Merrild and M. Runge, Detection of bearing faults in induction motors [M.S. thesis], Aalborg University, Esbjerg Campus, Esbjerg, Denmark, 2006. 

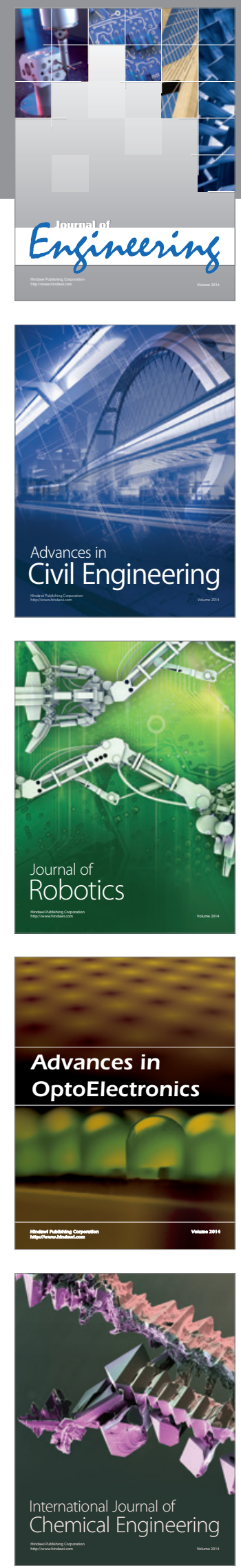

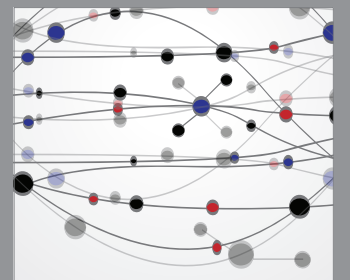

The Scientific World Journal
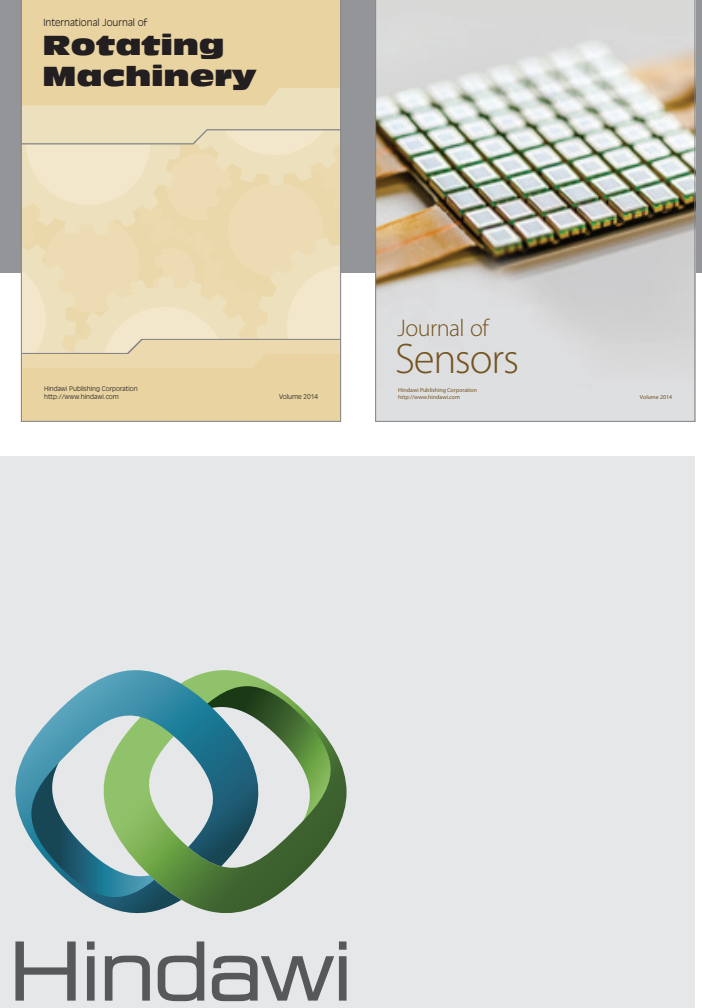

Submit your manuscripts at http://www.hindawi.com
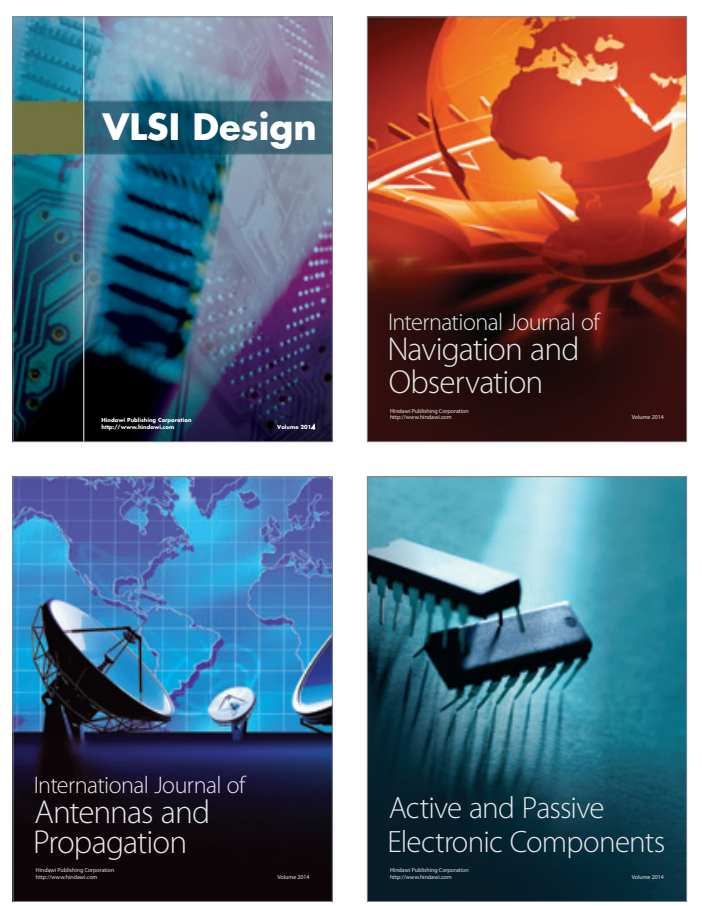
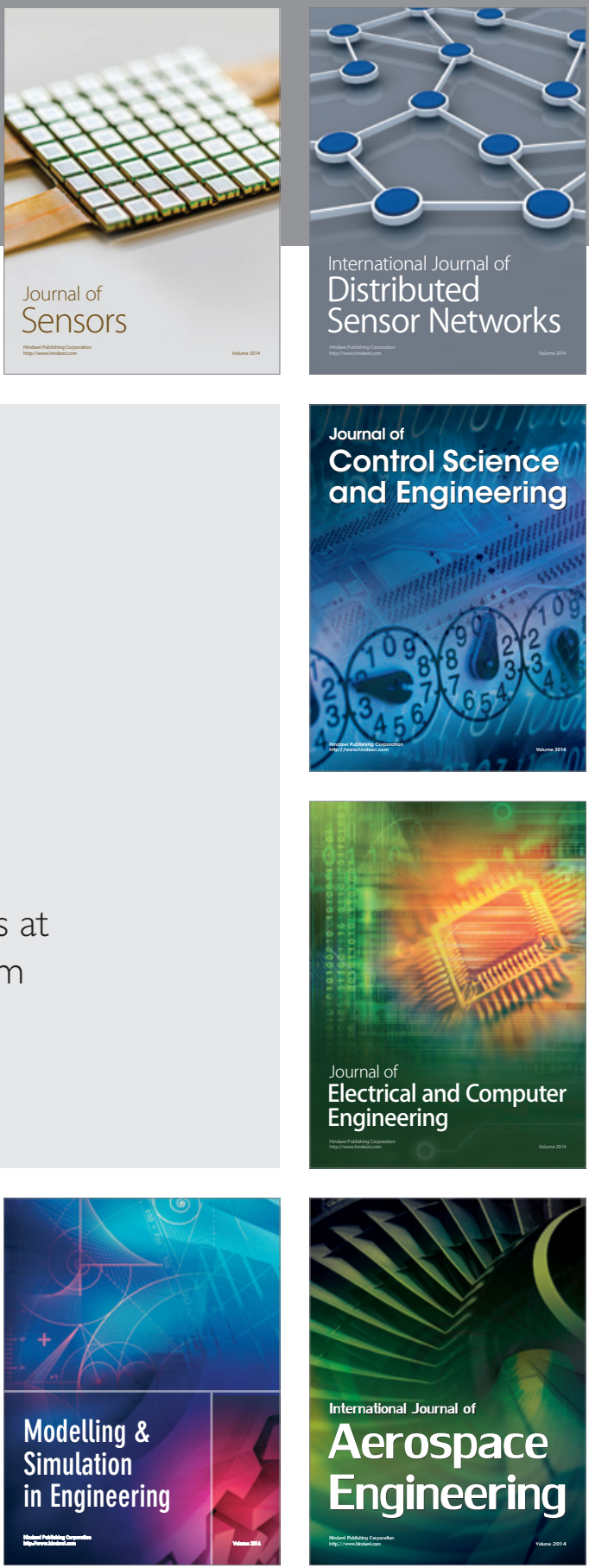

Journal of

Control Science

and Engineering
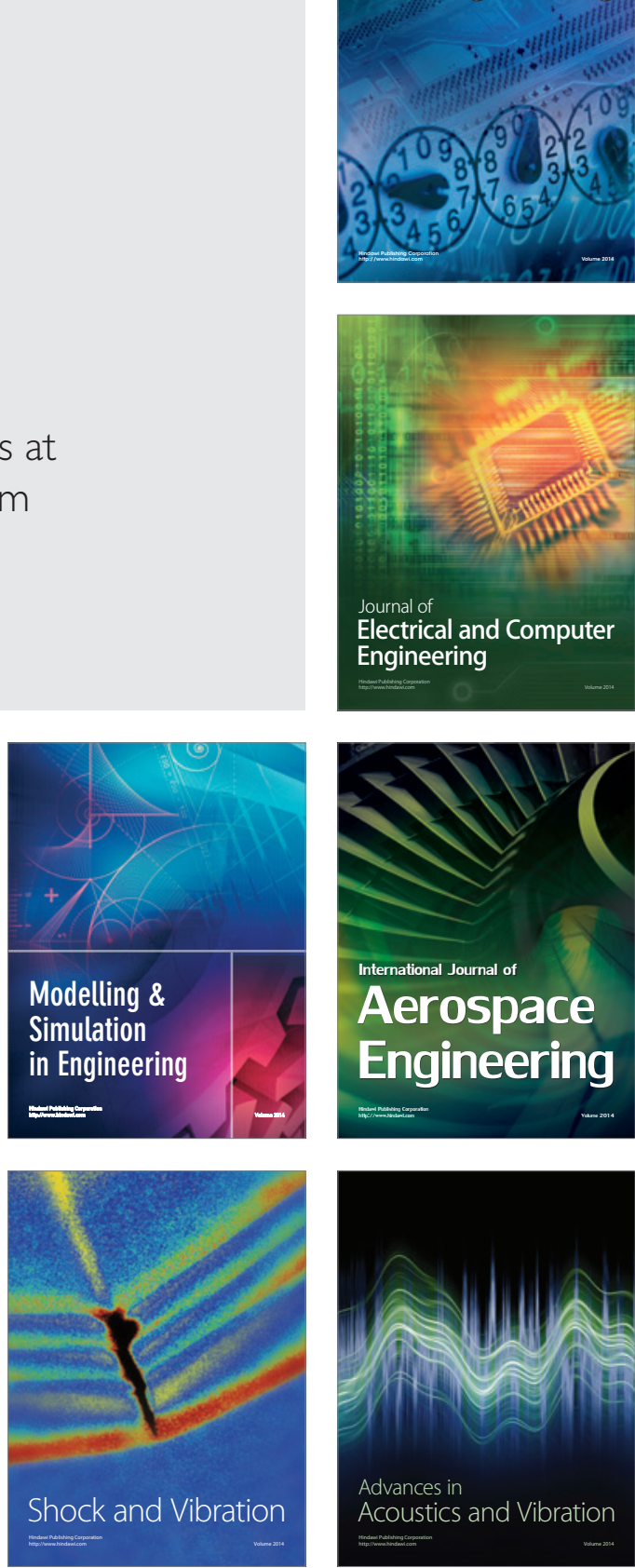